\title{
IUMRS-ICAM-93 Planned for Tokyo-Abstracts Still Being Accepted
}

Late abstracts are being accepted after the January 31, 1993 deadline for the Third IUMRS International Conference on Advanced Materials (IUMRS-ICAM-93). Abstracts must be received before April 30, however, to appear in the abstract book.

IUMRS-ICAM-93 is sponsored by the International Union of Materials Research Societies and organized by MRS-Japan. The conference will be held at Sunshine City, Tokyo, Japan from August 31 to September 4, 1993. The Meeting Chairs are Masao Doyama, Masaki Hasegawa, Shigeyuki Sōmiya and Shigehiko Yamada.

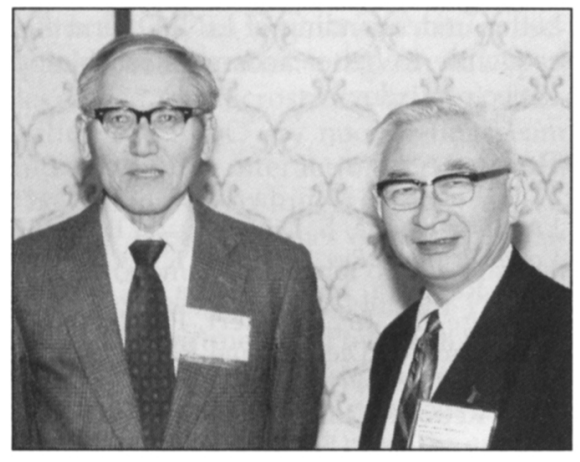

Two of the four Meeting Chairs for ICAM93, Masao Doyama (left) and Shigeyuki Sómiya, both of The Nishi-Tokyo University, prepare for The International Conference on Advanced Materials to be held in Japan, August 31-September 4.

\section{Technical Symposia}

The conference comprises 37 symposia, including Symposium X, Frontiers of Materials Science and Engineering, which consists of overviews for technical nonspecialists.
A: Composites
B: Glassy Materials
C: Powder Preparation
D: Computer Applications to Materials Science and Engineering (CAMSE '93)

E: Superplastic Phenomena in Ceramics, Intermetallics, and Composites

F: Materials Interconnection-Novel Approaches for Interconnection and Joining of Dissimilar Materials

G: Corrosion/Coating of Advanced Materials

$\mathrm{H}$ : Shape Memory Materials

I: Hydrogen Absorbing Materials and Hydride Batteries

$\mathrm{J}: \quad$ Structural Ceramics

K: Environmentally Conscious Materials
L: Rare-Earth Iron-Based Permanent Magnetic Materials

M: $C_{60}$ and Related Materials

$\mathrm{N}$ : Biomaterials

O: Catalytic Materials

P: Advanced Processing

Q: Ordered Polymers

R: Photo- and Electro-Responsive Materials

S: Electronic Materials and Processing for ULSI

$\mathrm{T}$ : Biosensors

U: Materials Synthesis and Modification by Ion Beams and/or Laser Beams

V: Materials for Information Storage Media

W: Fabrication of Silicon-Based Ceramics

$X$ : Frontiers of Materials Science and Engineering

Y: Diamond and Related Materials

$Z$ : Gradient Materials

AA: Grain and Interphase Boundaries

BB: Nanophase and Nanocomposite Materials

CC: Superlattices

DD: Surfaces and Interfaces

EE: Construction and Functions of Organic Thin Films

FF: Intelligent Materials

GG:Microgravity and Materials

HH: Superconducting Materials

II: Ferroelectrics

JJ: Nondestructive Evaluation

KK: Dielectric Materials

Symposium proceedings will be published in Transactions of MRS-Japan (publisher: MRS-Japan and Elsevier).

\section{Young Scientist Award}

The IUMRS-ICAM-93 is offering up to 10 awards for young scientists and engineers who are less than 35 years old. Applicants must be in recognized academic programs in materials-related fields and must be authors or co-authors at IUMRS-ICAM-93.

Each award will be a cash grant of $¥ 30,000$. Awards will be based on the presentation (oral or poster) and on the significance and timeliness of research results. Applicants should indicate "Young Scientist and Engineer Award Meeting" on their abstracts and should obtain a letter of support from their research supervisors.

Late applications for the Young Scientist award are being accepted until April 30.

\section{Registration}

The meeting registration fee before July 14,1993 is $¥ 49,000$ (about $\$ 390$ at current market prices). This fee includes MRSJapan 1994 membership and one volume of the proceedings. The hotel registration deadline is June 30.
To submit an abstract or obtain more detailed information, contact:

IUMRS-ICAM-93

c/o The Nikkan Kogyo Shimbun, Ltd.

Business Bureau

1-8-10 Kudan-kita, Chiyoda-ku, Tokyo 102, JAPAN.

Phone: 81-3-3222-7162

Fax: 81-3-3221-7137

\section{Additional Conferences}

The IUMRS-ICAM-93 is one in a series of conferences to be held in Japan at the end of the summer. The other conferences include the International Conference on Solid State Devices and Materials (August 29-September 1, 1993), Radiation Effects in Insulators-7 (September 6-10, 1993), and the Eighth International Conference on Surface Modification of Metals by Ion Beams (September 13-17, 1993).

\section{Yangtze Gorges Will Be Venue for IUMRS-ICA}

Immediately following the ICAM meeting, the first IUMRS International Conference in Asia (IRMRS-ICA) will hold its meeting, September 6-10, 1993. Organized by MRS-China, this conference will travel by boat along the Yangtze River from Wuhan to Chongging, a route known for its spectacular scenery. (IUMRS-ICA which involves MRS-China, MRS-India, MRS-Japan, MRS-Korea, and MRSTaiwan, will be held annually, rotating next to MRS-Taiwan and then to MRS-Korea).

The technical symposia for the upcoming meeting are:

Symposium A: Advanced Ceramics

Symposium B: Nanomaterials

Symposium C: Surface and Interfaces In addition, there will be a special session on Materials Education.

The registration fee is $\$ 300$ and includes a volume of extended abstracts and a volume of the proceedings. Registration for an accompanying person is $\$ 100$. Charge for the boat per person, including accommodations for 6 nights, meals, and festivities, is $\$ 750$. Space is limited to 150 people.

For further information, contact:

C-MRS

7 Baikshiqiao Rd.

Beijing 100081, China

Fax: 86-01-8412889

Tel: 86-01-8428640 